\title{
Renda Básica da Cidadania versus Imposto de Renda Negativo: O Papel dos Custos de Focalização
}

- Nelson Leitão PaEs*

\author{
- Marcelo Lettieri SiQueira**
}

\begin{abstract}
RESUMO
O presente artigo procura comparar duas políticas sociais alternativas de combate à pobreza e à desigualdade de renda no Brasil. A primeira é baseada na concessão de uma renda fixa universal, denominada Renda Básica da Cidadania (RBC), e a segunda, um Imposto de Renda Negativo (IRN), pago apenas às famílias com renda inferior a um determinado patamar. Para análise, adotou-se um modelo de equilíbrio geral computável. Os resultados mostraram que a RBC é melhor que o IRN quando o custo de focalização deste é superior a $50 \%$, e que para um custo menor que $50 \%$ o programa a ser adotado vai depender da estratégia de combate à pobreza escolhida.
\end{abstract}

\section{Palavras-Chave}

renda mínima, pobreza, modelo de equilíbrio geral computável

\section{ABSTRACT}

This paper compare two alternative social politics to reduce poverty and income inequality in Brazil. The first one is a payment of a universal fixed income, called Basic Income Grant (BIG), and the second one is a Negative Income Tax (NIT), pay only to the families with low incomes. For analysis, we use a Computable General Equilibrium Model. The results had shown that the BIG is better that NIT when the costs of administration associated with the NIT is higher than 50\%, and that for a cost between 0 and $50 \%$ the adopted program goes to depend on the strategy of poverty reduction.

\section{KEYWORDS}

basic income, poverty, computable general equilibrium model

\author{
Jel Classification \\ 138, C68, D58
}

\footnotetext{
* PIMES/UFPE. Endereço para contato: Centro de Ciências Sociais Aplicadas - UFPE - Av. Professor Morais Rego, s/n, Cidade Universitária. Recife - PE. CEP: 50.670-90I.E-mail: nlpaes@yahoo.com.br.

** CAEN/UFC. Endereço para contato: Av. da Universidade 2700, $2^{\circ}$ andar. Fortaleza - CE. CEP: 60.020-I8I. E-mail: marlettieri@gmail.com.

(Recebido em maio de 2006. Aceito para publicação em junho de 2007).
} 


\section{$1 \quad$ INTRODUÇÃO}

As duas últimas décadas foram marcadas por uma preocupação crescente e um intenso debate acerca das formas de combate à pobreza mundial. Por iniciativa da ONU, realizaram-se diversas conferências internacionais que culminaram no compromisso com os chamados objetivos do milênio. ${ }^{1}$ A maioria deles está intimamente relacionada ao enfrentamento da pobreza. Esta preocupação com a pobreza estendeu-se ao Brasil, que nos últimos anos passou a alocar expressivos recursos públicos em investimentos sociais.

No campo das ações, a literatura aponta que, embora o crescimento econômico seja condição básica para a redução da pobreza, há também a necessidade da criação de mecanismos capazes de atingir os mais pobres de forma efetiva. Para superar este desafio, vários países têm retomado a discussão acerca dos impactos dos programas de transferência de renda sobre a pobreza e a desigualdade.

Segundo Lavinas (1999), podem ser identificados basicamente dois tipos de programas de renda mínima: um, baseado na garantia de um imposto de renda negativo (IRN) a todos aqueles que não dispõem do mínimo para sua sobrevivência; e outro, denominado Renda Mínima Universal (RMU), que tem como objetivo a transferência incondicional de uma renda básica de mesmo valor a todos os indivíduos. ${ }^{2}$

O que esses programas têm em comum é a idéia de racionalização dos sistemas nacionais de proteção social, o que significa a substituição das diferentes modalidades de benefícios por uma renda monetária única, permitindo aos beneficiários buscarem atender, diretamente no mercado, as suas necessidades básicas. A grande dificuldade da RMU é que se o seu objetivo for reduzir a pobreza, o benefício deve ser relativamente elevado, o que tornaria o programa excessivamente caro. Já o IRN apresenta três desvantagens: 1) supõe que os recursos reais dos indivíduos sejam conhecidos; 2) requer enquetes sobre as rendas e as relações familiares; e 3) não pode ser concedido no exercício fiscal da obtenção das rendas. Os dois primeiros compõem o denominado custo de focalização do IRN, que é zero no caso da RMU.

1 Em 2000, a ONU (Organização das Nações Unidas), ao analisar os maiores problemas mundiais, estabeleceu oito Objetivos do Milênio: acabar com a fome e a miséria, educação básica de qualidade para todos, igualdade entre sexos, reduzir a mortalidade infantil, melhorar a saúde da gestante, combate à AIDS, malária e outras doenças, respeito ao meio ambiente e todos trabalhando pelo desenvolvimento.

2 No Brasil, uma primeira tentativa de se adotar um IRN foi através do projeto de lei $\mathrm{n}^{\circ}$ 80, de 1991, do Senador Eduardo Suplicy. Não tendo sido implementado, o projeto foi substituído por um outro que previa uma RMU. Este foi aprovado, dando origem à Lei N. ${ }^{\circ} 10.835$, de $08 / 01 / 2004$, que instituiu a Renda Básica da Cidadania. 
Para os que advogam que, em função das restrições orçamentárias, somente uma política socialmente focalizada no pobre terá resultados expressivos ${ }^{3}$, o IRN seria a escolha ideal. Por outro lado, os defensores da RMU alegam que o IRN interfere mais intensamente nas decisões de trabalho, desestimulando-o, e que o custo de focalização do IRN pode comprometer boa parte dos recursos do programa, o que justificaria a adoção da RMU.

Nesse contexto, a principal motivação deste artigo é saber em que medida a presença dos custos de focalização altera a escolha entre programas sociais universais (como a RMU) e programas seletivos (como o IRN). Para isso, adotou-se um modelo de equilíbrio geral computável (MEGC), que, ao representar o comportamento de diversos agentes, permite que sejam simuladas as respostas dos indicadores de pobreza e desigualdade à adoção de cada um desses programas e permite, também, que se analise o impacto dos programas sobre outras variáveis econômicas.

A literatura contém um grande número de trabalhos que aplicam a abordagem do Equilíbrio Geral Computável (EGC) para temas relacionados à pobreza e distribuição de renda. Iniciou-se com Adelman e Robinson (1976), e inclui também os trabalhos de Bourguignon et al. (1991), Khan (1999) e Muller et al. (2004). No Brasil, pode-se citar os trabalhos de Cury (1998) e Barros et al. (2000). Entretanto, diferentemente da modelagem seguida pelos autores nacionais, em que predominam exercícios de estática comparativa, neste artigo privilegiou-se a formulação dinâmica do modelo, de maneira a se analisar os efeitos de transição decorrentes das propostas consideradas.

O MODELO

\subsection{Especificação do Modelo}

A análise de equilíbrio geral aqui proposta baseia-se no modelo neoclássico de acumulação de capital com utilização de tempo discreto. A economia artificial é fechada, determinística, com população e tecnologia constantes. ${ }^{4}$

3 Esse é o entendimento geral da maioria dos estudiosos da pobreza no Brasil. Ver Henriques (2000).

4 Com a população crescendo a uma taxa constante, o produto deverá crescer à mesma taxa, o que não deve afetar a proposta da Renda Básica da Cidadania detalhada a seguir. Por outro lado, os salários serão um pouco menores, o que tende a aumentar a demanda pelo IRN refletindo em menores benefícios. Portanto, o crescimento da população é relativamente favorável à primeira proposta em relação à segunda. 
As famílias são heterogêneas, sendo diferenciadas pela renda, pela possibilidade de poupar e pelo nível de consumo. Há apenas uma única firma representativa que age de forma competitiva na produção de um único bem.

Todas as famílias fornecem mão-de-obra para a firma, mas apenas as que poupam fornecem capital. Em troca, a firma paga salários e juros. Cada família escolhe o quanto consumir, sujeita a restriçôes orçamentárias. A renda das famílias é gasta ou toda em consumo (no caso daquelas que não poupam), ou em consumo e poupança (para as que poupam), sendo esta última representada no modelo pelo estoque de capital físico.

\subsubsection{Familias}

O modelo conta com nove famílias representativas, com vida infinita, cada qual com faixa de renda diferente. Para a diferenciação da renda das famílias, supõe-se que cada uma possui uma produtividade por hora trabalhada diferente e fixa.

O problema de cada família é maximizar a sua utilidade, dada por uma função logarítmica, respeitando a sua restrição orçamentária. As famílias serão divididas em três grupos: as famílias que não poupam e cujo consumo per capita está abaixo da linha de indigência ${ }^{5}$ (tipo I), as que não poupam, mas cujo consumo per capita está acima da linha de indigência (tipo II) e as que poupam (tipo III). Deve-se ressaltar que a POF 2002/2003 contempla uma série de rendimentos que por simplicidade foram agrupados em três tipos de renda. De maneira geral, os rendimentos do trabalho, conta própria, aposentadoria privada, pensão alimentícia, transferência transitória e rendimentos não-monetários foram considerados como renda do trabalho; aposentadoria pública e bolsa de estudo foram consideradas como transferência pública; e rendimentos do empregador, aluguéis, aplicações de capital, empréstimos e vendas esporádicas foram consideradas renda do capital. Como será visto a seguir, as famílias tipos I e II têm renda de até 5 salários mínimos e, para estes grupos, as rendas de capital representaram menos de $2,5 \%$ do total de rendimentos, tendo sido tal valor incorporado ao rendimento do trabalho e adotada a hipótese de que estas famílias não poupam e que, portanto, não possuem rendimento do capital.

5 Conceitualmente, a linha de indigência refere-se aos custos de uma cesta alimentar que atenda às necessidades de consumo calórico mínimo de um indivíduo. Conforme o trabalho Mapa do Fim da Fome 2, do economista Marcelo Néri (FGV), a linha de indigência representa $1 / 2$ salário mínimo, o equivalente a R\$ 100,00 em 2002. 


\section{a) Familias Tipo I}

As famílias tipo I resolvem um problema dinâmico, tomando preços e parâmetros fiscais como dados e escolhem as seqüências de consumo que maximizam a sua função utilidade (1), obedecida a restrição orçamentária (2).

$$
U_{i}=\sum_{t=0}^{\infty} \beta^{t}\left[\ln \left(c_{i t}\right)+\gamma_{i} \ln \left(g_{t}\right)\right]
$$

As famílias do tipo I possuem consumo per capita inferior à linha de indigência. Assim, para estas famílias há uma necessidade tão premente em relação ao consumo que toda a sua utilidade deriva do atendimento às suas necessidades alimentares mínimas. Não há espaço aqui para a clássica escolha consumo x lazer, uma vez que este grupo de famílias não atinge sequer o mínimo necessário de alimentos. As famílias consomem tudo o que recebem de salários e de transferências governamentais.

$$
\left(1+\tau_{c t}^{i}\right) c_{i t} \leq\left(1-\tau_{h t}^{i}\right) \xi_{i} w_{i t} h_{i t}+T_{i t}
$$

onde $\beta$ é o fator de desconto intertemporal, $c_{i t}$ é o consumo da família $i$ no tempo $t$ e $g_{i}$ é o peso dos bens públicos, $g_{t}$, na utilidade da família $i, \tau_{c t}^{i}$ é a alíquota do imposto sobre o consumo pago pela família $i$ no tempo $t, \tau_{h t}^{i}$ é a alíquota do imposto sobre a renda do trabalho pago pela família $i$ no tempo $t$, $w_{i t}$ é o salário por hora de trabalho antes dos impostos que a família $i$ recebe pelo trabalho no tempo $t, \xi_{i}$ é a produtividade da família $i^{6} T_{i t}$ é a transferência governamental recebida pela família $i$ no tempo $t$ e $h_{i}$ é o total de horas trabalhadas pela família $i$.

Para a maximização da utilidade basta apenas que cada família consuma toda a sua renda. Assim, a seqüência ótima de consumo para as famílias do tipo I é:

$$
c_{i t}=\frac{\left[\left(1-\tau_{h t}^{i}\right) \xi_{i} w_{i t} h_{i t}+T_{i t}\right]}{\left(1+\tau_{c t}^{i}\right)}
$$

6 Por hipótese, a produtividade é fixa e não há a possibilidade de uma família tentar aumentá-la ou igualála à de outra família. 


\section{b) Familias Tipo II}

As famílias tipo II escolhem as sequiências de consumo e horas de trabalho que maximizam a sua função utilidade (4), considerando a restrição orçamentária (5), tomando preços e parâmetros fiscais como dados:

$$
U_{i}=\sum_{t=0}^{\infty} \beta^{t}\left[\alpha_{i} \ln \left(c_{i t}\right)+\gamma_{i} \ln \left(g_{t}\right)+\left(1-\alpha_{i}\right) \ln \left(1-h_{i t}\right)\right]
$$

A restrição orçamentária é similar à do tipo $\mathrm{I}$, com as famílias consumindo tudo o que recebem de salários e de transferências governamentais, mas com o consumo sendo necessariamente superior à linha de indigência. ${ }^{7}$

$$
\begin{aligned}
& \left(1+\tau_{c t}^{i}\right) c_{i t} \leq\left(1-\tau_{h t}^{i}\right) \xi_{i} w_{i t} h_{i t}+T_{i t} \\
& c_{i t} \geq \text { L.I. }
\end{aligned}
$$

Resolvendo o Lagrangeano correspondente ao problema acima, encontram-se as seqüências ótimas de consumo e horas de trabalho:

$$
\begin{aligned}
& c_{i t}=\frac{\alpha_{i}\left[\left(1-\tau_{h t}^{i}\right) \xi_{i} w_{i t}+T_{i t}\right]}{\left(1+\tau_{c t}^{i}\right)} \\
& h_{i t}=1-\frac{\left(1-\alpha_{i}\right)\left(1+\tau_{c t}^{i}\right) c_{i t}}{\alpha_{i}\left(1-\tau_{h t}^{i}\right) \xi_{i} w_{i t}}
\end{aligned}
$$

\section{c) Familias Tipo III}

As famílias tipo III resolvem um problema dinâmico similar ao do tipo II, com preços e parâmetros fiscais dados, e escolhem as seqüências de consumo, estoques de capital e títulos públicos, no período seguinte, que maximizam a sua função utilidade (4). Elas, entretanto, devem obedecer a duas novas restriçóes: (i) uma nova restrição orçamentária (8) e (ii) uma restrição de acumulação de capital (9).

$$
\begin{aligned}
& \left(1+\tau_{c t}^{j}\right) c_{j t}-T_{j t}+I_{j t} \leq\left(1-\tau_{h t}^{j}\right) \xi_{j} w_{t} h_{j t}+\left(1-\tau_{k t}\right) r_{t} k_{j t} \\
& k_{j t+1}=(1-\delta) k_{j t}+I_{j t}
\end{aligned}
$$

Além disso, impõe-se que $k_{j t}>0$.

7 Note que as famílias do tipo II, apesar de pobres, já atenderam às suas necessidades alimentares mínimas, abrindo espaço para a inclusão do lazer na função utilidade. 
Aqui, $r_{t}$ é o preço antes dos impostos sobre o aluguel do capital no tempo $t, k_{j t}$ representa o estoque de capital da família $j$ no tempo $t, \tau_{l t}$ é a alíquota do imposto sobre a renda do capital pago pelas famílias que poupam e $I_{j t}$ é o investimento em capital realizado pela família $j$ no tempo $t$.

Pode-se juntar as duas restrições acima numa só e se obter as condições de primeira ordem do problema:

$$
\begin{aligned}
& h_{j t}: \beta^{t} \frac{\left(1-\alpha_{j}\right)}{\left(1-h_{j t}\right)}=\lambda_{j t}\left(1-\tau_{h t}^{j}\right) \xi_{j} w_{j t} k_{j t} \\
& c_{j t}: \beta^{t} \frac{\alpha_{j}}{c_{j t}}=q_{t} \lambda_{j t}\left(1+\tau_{c t}^{j}\right) \\
& k_{j t+1}: \lambda_{j t}=\lambda_{j t+1}\left[(1-\delta)+\left(1-\tau_{k t+1}\right) r_{t+1}\right]
\end{aligned}
$$

Fazendo substituições recursivas, usando sucessivas restrições orçamentárias (8) para eliminar os termos $k_{j t+m}$, obtém-se o valor presente desta restrição. E assim, como condição de otimalidade, impõe-se a seguinte condição de transversalidade:

$$
\lim _{T \rightarrow \infty} \beta^{T} k_{j T+1}=0
$$

\subsubsection{Firma Representativa}

A firma representativa é competitiva, com função de produção Cobb-Douglas, e escolhe as quantidades de insumos e produto que maximizam o seu lucro.

$$
\sum_{t=0}^{\infty}\left[Y_{t}-w_{t} H_{t}-r_{t} K_{t}\right] \quad \operatorname{com} \quad Y_{t}=K_{t}^{\theta} H_{t}^{1-\theta}
$$

onde $\theta$ é a participação do capital na renda, $Y_{t}$ é o produto, $K_{t}$ é o estoque de capital agregado e $H_{t}$ é o número de horas trabalhadas. Maximizando os lucros, obtém-se a taxa de juros e o salário:

$$
r_{t}=\theta K_{t}^{\theta-1}\left(H_{t}\right)^{1-\theta}
$$




$$
w_{t}=(1-\theta) K_{t}^{\theta}\left(H_{t}\right)^{-\theta}
$$

\subsubsection{Governo}

O governo arrecada impostos das famílias para financiar seus gastos e transferências. A restrição orçamentária do governo é dada por:

$$
\Gamma_{t}=T_{t}+g_{t}
$$

onde $\Gamma_{t}$ é a arrecadação tributária no tempo $t$ e $T_{t}$ é o total de transferências no tempo $t$.

\subsubsection{Equilibrio}

Na economia artificial supradescrita, as famílias do tipo I escolherão as seqüências de consumo $\left\{c_{i t}\right\}$; as do tipo II, as seqüências de consumo e horas de trabalho $\left\{c_{i t}, h_{i}\right\}$ e as do tipo III, a seqüência $\left\{c_{i t}, h_{i t}, k_{i t}\right\}$, que maximizam as suas utilidades, dada a restrição orçamentária de cada uma. A firma escolhe $\left\{K_{t}, H_{t}\right\}$ de forma a maximizar seus lucros.

Antes de prosseguir, é necessário introduzir alguns conceitos fundamentais para a análise que será feita adiante.

Definição 1. Uma politica fiscal plausivel do governo é uma seqüência de alíquotas tributárias, de despesas e de transferências que satisfazem a restrição do governo (17).

Definição 2. Uma alocação plausivel é uma sequiência de consumo, horas trabalhadas e estoque de capital físico, $\left\{C_{t}, H_{t}, K_{t}\right\}$, que satisfaz a seguinte restrição agregada:

$$
C_{t}+\left[K_{t+1}-(1-\delta) K_{t}\right]+g_{t}=K_{t}^{\theta} H_{t}^{1-\theta}
$$

Em (18), $C_{t}$ denota a soma do consumo de cada família, ponderada pelo tamanho da população que cada família representa $\left(\eta_{i}\right)$. Esta mesma caracterização aplica-se para os salários, estoque de capital e as transferências. 
Definição 3. Um equilíbrio competitivo com tributos distorcivos é composto por uma política fiscal compatível com a restrição orçamentária do governo, uma alocação plausível e um sistema de $\operatorname{preços}^{8}$ tal que, dado o sistema de preços e a política fiscal, a alocação resolve os problemas da firma e das famílias.

Para o cálculo do equilíbrio devemos resolver o sistema de equações de diferenças não-lineares composto por (3), (6), (7), (10) a (12), (15), (16), (17) e (18), dado $k_{j 0}$ e com a condição terminal dada por (13).

Começamos substituindo (11) e (15) em (12), obtendo a dinâmica do consumo das famílias que poupam (tipo III):

$$
c_{j t+1}=\frac{\left(1+\tau_{c t}^{j}\right)}{\left(1+\tau_{c t+1}^{j}\right)}\left[(1-\delta) \beta+\left(1-\tau_{k t+1}\right) \beta \theta K_{t+1}^{\theta-1} H_{t+1}^{1-\theta}\right] c_{j t}
$$

Substituindo (11) e (16) em (10) obtemos a condição para as horas trabalhadas das famílias que poupam:

$$
h_{j t}=1-\frac{\left(1-\alpha_{j}\right)\left(1+\tau_{c t}^{j}\right) c_{j t}}{\alpha_{j}\left(1-\tau_{h t}^{j}\right)(1-\theta) \xi_{j} K_{t}^{\theta} H_{t}^{-\theta}}
$$

Substituindo (16) em (6) e (7) obtemos, por sua vez, o consumo e as horas trabalhadas das famílias tipo II:

$$
\begin{aligned}
& c_{i t}=\frac{\alpha_{i}}{\left(1+\tau_{c t}^{i}\right)}\left[\left(1-\tau_{h t}^{i}\right)(1-\theta) \xi_{i} K_{t}^{\theta} H_{t}^{-\theta}+T_{i t}\right] \\
& h_{i t}=1-\frac{\left(1-\alpha_{i}\right)\left(1+\tau_{c t}^{i}\right) c_{i t}}{\alpha_{i}\left(1-\tau_{h t}^{i}\right)(1-\theta) \xi_{i} K_{t}^{\theta} H_{t}^{-\theta}}
\end{aligned}
$$

E finalmente, substituindo (16) em (3), obtém-se o consumo das famílias mais pobres, as do tipo I:

$$
c_{i t}=\frac{1}{\left(1+\tau_{c t}^{i}\right)}\left[\left(1-\tau_{h t}^{i}\right)(1-\theta) \xi_{i} K_{t}^{\theta} H_{t}^{-\theta} h_{i t}+T_{i t}\right]
$$

O algoritmo implementado para o cômputo do equilíbrio acima definido baseia-se no método comumente conhecido como de tentativa e erro ("shooting"). A idéia é resolver

8 O sistema de preços é formado pelo preço do trabalho (salários), do capital (aluguel) e o do bem único nesta economia, este último adotado como numerário. 
o problema com dois valores de contorno, procurando pelos $c_{j 0}$ que façam com que cada uma das equações de Euler (19) e a restrição agregada (18) impliquem um $\tilde{k}_{S} \approx \tilde{k}$, em que $S$ representa um número grande o suficiente e $\tilde{k}$ o capital por trabalho efetivo no estado estacionário associado à política fiscal que está sendo analisada. Ao final do algoritmo, estarão determinadas as seqüências de $c_{i}, c_{j}, h_{i}, h_{j}, H$ e $K{ }^{9}$ Logo, utilizando as demais equações do modelo pode-se calcular as outras variáveis, $r_{t}, g_{t}, w_{i t}$ e $k_{j t}$.

\subsection{Calibragem do Modelo}

A descrição e análise detalhada da calibragem dos parâmetros não serão desenvolvidas nesta seção, mas constam do anexo.

\section{POLÍTICAS ANALISADAS}

São duas as propostas a serem analisadas, que contemplam duas estratégias diferentes no enfrentamento da pobreza e desigualdade. A primeira é a Renda Básica da Cidadania - RBC, cujo benefício é universal, concedido a todos os brasileiros, enquanto a segunda é o Imposto de Renda Negativo - IRN, uma política social seletiva, cujo benefício é calculado individualmente de forma a fazer com que a renda familiar atinja um determinado patamar mínimo. Evidentemente, neste segundo caso há dificuldades relevantes em se identificar não só a família apta a receber o benefício como também o valor que lhe será entregue. Trata-se do conhecido custo de focalização e representa quanto do orçamento do programa é gasto na identificação do beneficiário e/ou desviado para famílias que não deveriam receber o benefício. ${ }^{10} \mathrm{~A}$ principal motivação do trabalho é saber em que medida a presença dos custos de focalização altera a escolha entre programas sociais universais e programas seletivos.

9 No algoritmo de solução calcula-se $K_{t+1}$ pela equação (18) e $H_{t+1}$ por (19) a (24). Após os $S$ períodos compara-se a relação $k_{S}=K_{S} / H_{S}$ com $k$ para se determinar a solução do problema ou realizar nova iteração.

10 Harberger (2003) levanta uma série de problemas potenciais que poderiam incidir sobre o imposto de renda negativo, notadamente na identificação dos beneficiários. Segundo o autor, para conter abusos haveria necessidade de uma série de filtros limitando os beneficiários do programa, aumentando os custos administrativos e elevando o potencial de fraudes. 


\subsection{Proposta 1 - Renda Básica da Cidadania (Lei N. ${ }^{0} 10.835$, de 08/01/2004)}

Por esta proposta, aprovada recentemente no Congresso Nacional, cada brasileiro faria jus ao recebimento de uma quantia fixa a título de Renda Básica da Cidadania (RBC).

A Lei, entretanto, não é clara em relação ao valor exato dessa transferência, estabelecendo, tão-somente, que

O pagamento do benefício deverá ser de igual valor para todos, e suficiente para atender às despesas minimas de cada pessoa com alimentação, educação e saúde, considerando para isso o grau de desenvolvimento do País e as possibilidades orçamentárias.

No entanto, o Brasil não tem possibilidade orçamentária de atender, por meio de transferências diretas, às necessidades mínimas de cada cidadão com alimentação, saúde e educação. Se um salário mínimo fosse suficiente para cobrir tais necessidades (o que não é), teríamos, em 2002, um custo de mais de 30\% do PIB, quase o valor da arrecadação tributária. Fica claro, portanto, que o que irá condicionar o valor do benefício é a restrição orçamentária do governo e não as necessidades da população. Sendo assim, optou-se aqui por um benefício equivalente a R \$ 50,00 por família, valor do benefício básico do bolsa-família, instituído pela Lei n. ${ }^{\circ} 10.836$, de 09 de janeiro de 2004. Este valor implica um custo aproximado de 2,09\% do PIB.

A Lei também prevê que o benefício deve começar a ser pago a partir de 2005, devendo ser implementado de forma a beneficiar inicialmente as camadas da população mais necessitadas, expandindo-se gradualmente até atingir todos os brasileiros.

Com relação ao financiamento, seguiu-se aqui a sugestão do Senador Eduardo Suplicy, segundo a qual o programa seria assumido integralmente pelo governo federal, com recursos a serem obtidos com a desativação gradual de programas sociais compensatórios.

A implementação da proposta da renda básica da cidadania altera o modelo pela inclusão de um valor de transferências de $\mathrm{R} \$ 50,00$ por família $(\Delta \mathrm{T}=0,0115)$ e pela redução das despesas do governo em montante equivalente a 2,09\% do PIB. Como a Lei $10.835 / 2004$ prevê a implantação gradativa do programa, propõe-se que a partir de 2005 os dois grupos de famílias mais pobres (até 1/2 salário mínimo) recebam o benefício, passando em 2007 a abranger as demais famílias com renda de até 5 salários mínimos e que finalmente em 2010 alcance toda a população. 


\subsection{Proposta 2 - Um Imposto de Renda Negativo}

O Imposto de Renda Negativo ${ }^{11}$ (IRN) é um instrumento de política social que garante aos cidadãos beneficiados um valor mínimo de renda em dinheiro, e por isso é comumente denominado Programa de Garantia de Renda Mínima (PGRM). Caso a renda do cidadão não alcance o mínimo determinado, ele recebe um complemento financeiro para que sua renda atinja aquele patamar. Os recursos para a concessão dos benefícios podem vir de rubricas específicas do orçamento público destinadas ao programa ou da realocação de outros gastos (sociais ou não). Era esta a idéia inicial do Senador Suplicy em 1991 quando propôs o programa, que desta forma beneficiaria apenas a população com renda abaixo de determinado valor mínimo.

Friedman (1975) foi quem originalmente propôs o IRN em seu livro Capitalismo e Liberdade, num breve capítulo sobre o sistema de assistência social. A fórmula para o benefício (B) recebido pelo indivíduo deveria ser:

$$
B=G-t_{I R N} Y
$$

onde $G$ é a renda mínima garantida, $Y$ é a renda própria do trabalhador (que pode ser zero) e $\boldsymbol{t}_{I R N}$ é a alíquota do IRN.

\subsubsection{Especificação da Proposta}

A proposta, aqui, é construir um IRN que tenha o mesmo custo da proposta especificada em 3.1 (Renda Básica da Cidadania), de forma a permitir uma comparação dos efeitos de ambas, dado que custariam o mesmo para o governo. As datas para a implantação do programa também seriam as mesmas, bem como a forma de financiamento.

Para isso, restringiu-se o benefício total desta proposta $(\Delta)$ a $2,09 \%$ do PIB, ou seja:

$$
\Delta=\sum_{i=1}^{5} B_{i}=0,0209 P I B
$$

O benefício deve ser concedido a todas as famílias que recebem até 5 salários mínimos (famílias 1 a 5). Assim, $G$ e $t$ devem ser tais que $B_{i}=0$ para renda familiar maior que $5 \mathrm{SM}$, ou seja: $G-t . Y_{i}=0$, ou $G=t . Y_{i}$, para todo $Y_{i}>5 S M$. Como a renda do trabalho da família $i\left(Y_{i}\right)$ é dada por $w_{i} h_{i}$, de (25) tem-se:

11 Para uma discussão completa sobre o IRN, ver Moffitt (2003). 


$$
0,0209 P I B=\sum_{i=1}^{6} \eta_{i}\left(G-t w_{i} h_{i}\right)
$$

Conjugando (26) com a restrição $G=t w_{i} h_{i}$ para $Y i>5 S M$, e substituindo os valores das variáveis para cada família chega-se, aproximadamente, aos seguintes valores: $t$ $=11,3 \%$ e $G=0,0347$ (o equivalente a R $\$ 113,00$ ). Logo, o IRN terá a seguinte fórmula de incidência:

$$
\Delta=0,0347-0,113 w_{i} h_{i}
$$

A análise procedida até o momento pressupõe que inexistem custos de focalização. Para incluí-los, supõe-se que se referem totalmente a desvios do benefício para indivíduos que não se enquadrariam na condição de beneficiários. Como esta condição é representada pela renda, significa que famílias com renda superior a 5 S.M. receberiam indevidamente uma parte dos recursos destinados aos mais pobres. ${ }^{12}$

A análise dos efeitos do custo de focalização é central neste trabalho. Busca-se determinar até que ponto a presença deles faria com que a escolha do programa social a ser adotado se modificasse. Para a análise consideraram-se três percentuais de custos: $25 \%, 50 \%$ e $75 \%$ dos recursos destinados ao programa do IRN. Pressupóe-se que o valor do custo de focalização se distribui igualmente entre as famílias não abrangidas pelo IRN. Assim, o custo de focalização altera não só os valores da renda mínima familiar $(G)$ e da alíquota do IRN $(t)$, mas também "cria" um benefício para as famílias que poupam, conforme tabela abaixo:

\section{TABELA I - PARÂMETROS DO IRN COM CUSTO DE FOCALIZAÇÃO}

\begin{tabular}{lccc}
\hline Custo de Focalização (\% dos recursos do programa IRN) & $25 \%$ & $50 \%$ & $75 \%$ \\
\hline Renda Mínima Familiar (G) & 0,0260 & 0,0174 & 0,0087 \\
& $(\mathrm{R} \$ 84,92)$ & $(\mathrm{R} \$ 56,61)$ & $(\mathrm{R} \$ 29,31)$ \\
Alíquota do IRN $(t)$ & $8,5 \%$ & $5,7 \%$ & $2,8 \%$ \\
Transferência Uniforme Famílias com Renda acima de 5 S.M. (TU) & 0,0059 & 0,0118 & 0,0177 \\
& $(\mathrm{R} \$ 19,22)$ & $(\mathrm{R} \$ 38,43)$ & $(\mathrm{R} \$ 57,65)$ \\
\hline
\end{tabular}

Fonte: Elaboração Própria.

12 Uma segunda fonte do custo de focalização refere-se às despesas necessárias à comprovação da renda efetiva. Tal custo não foi considerado explicitamente neste trabalho, mas pode-se argumentar que parte substancial dele se transforma em renda para famílias que não estão cobertas pelo programa, uma vez que este custo se trata da compra de materiais e equipamentos para controle, revertidos em renda para empresários e trabalhadores dos fornecedores, e contratação de mão-de-obra. Com isto, esta segunda fonte de focalização já estaria refletida, em parte, no custo de focalização coberto pelo trabalho. 


\subsubsection{Inclusão no Modelo}

Para inclusão dessa proposta no modelo basta alterar as restrições orçamentárias do governo e das famílias de forma que se tenha:

Restrição orçamentária das familias que ganham até 5 SM:

$$
\left(1+\tau_{c t}^{i}\right) c_{i t} \leq\left(1-\tau_{h t}^{i}-t\right) w_{i t} h_{i}+\left(T_{i t}+G\right)
$$

Restrição orçamentária das familias que ganbam mais de 5 SM:

$$
\left.\left(1+\tau_{c t}^{j}\right) c_{j t}-T_{j t}-T U_{j t}+I_{j t} \leq\left(1-\tau_{h t}^{j}\right) \xi_{j} w_{t} h_{j t}+\left(1-\tau_{k t}\right) r_{t} k_{j t}\right)
$$

Restrição orçamentária do governo:

$$
\Gamma_{t}=T_{t}+\left(g_{t}-\Delta_{t}\right)+\Delta_{t}
$$

\section{RESULTADOS}

Nesta seção, serão apresentados os resultados das simulações das propostas. Serão verificados aspectos relativos à redução da pobreza e desigualdade, bem como seus efeitos macroeconômicos. Tais resultados servirão de base para considerações a respeito da escolha da política social mais adequada quando se considera a presença dos custos de focalização.

\subsection{Benefícios Monetários}

Dadas as especificações das propostas, pôde-se calcular o benefício monetário a que fará jus cada uma das famílias. A Tabela 2 a seguir apresenta um resumo desses benefícios.

Analisando a Tabela 2, pode-se constatar claramente a vantagem da proposta do IRN para os mais pobres quando não há custo de focalização: enquanto, na primeira proposta, todos recebem $\mathrm{R} \$ 50,00$ de benefício, na segunda, os muito pobres recebem de R \$ 98,58 a R \$110,43, com valores decrescentes com a renda. Os valores dos benefícios monetários são superiores na proposta do IRN devido basicamente aos ganhos decorrentes da focalização. Programas de transferência de renda devem concentrar seus recursos naqueles que mais necessitam e este não é o caso da pro- 
posta da Renda Básica da Cidadania, que propõe um benefício universal e, portanto, fornece valores mais baixos do que o IRN para as famílias mais pobres e proporciona recursos para os mais ricos.

\section{TABELA 2 - VALORES DOS BENEFÍCIOS POR FAMÍLIA NO LONGO PRAZO}

\begin{tabular}{|c|c|c|c|c|c|c|c|}
\hline \multirow[b]{2}{*}{ Faixas de Renda (SM) } & \multicolumn{2}{|l|}{$\mathrm{RBC}$} & \multicolumn{2}{|c|}{ IRN s/ Custo } & \multicolumn{3}{|c|}{ IRN Custo $25 \%$} \\
\hline & Benefício (R\$) & $\begin{array}{c}G \\
(\mathrm{R} \$)\end{array}$ & $\begin{array}{l}t_{I R N} \\
(\%)\end{array}$ & Benefício $(\mathrm{R} \$)$ & $\begin{array}{c}G \\
(\mathrm{R} \$)\end{array}$ & $\begin{array}{l}t_{I R N} \\
(\%)\end{array}$ & Benefício $(\mathrm{R} \$)$ \\
\hline ATÉ $1 / 4$ & 50,00 & & & 110,43 & & & 82,82 \\
\hline DE $1 / 4$ A $1 / 2$ & 50,00 & & & 106,80 & & & 80,10 \\
\hline $\mathrm{DE} 1 / 2 \mathrm{~A} 1$ & 50,00 & & & 98,58 & & & 73,93 \\
\hline DE 1 A 2 & 50,00 & & & 91,22 & & & 65,89 \\
\hline DE 2 A 3 & 50,00 & 113,23 & 11,3 & 90,69 & 84,92 & 8,5 & 65,26 \\
\hline DE 3 A 5 & 50,00 & & & 67,94 & & & 47,98 \\
\hline DE 5 A 10 & 50,00 & & & 0,00 & & & 19,22 \\
\hline DE 10 A 20 & 50,00 & & & 0,00 & & & 19,22 \\
\hline ACIMA DE 20 & 50,00 & & & 0,00 & & & 19,22 \\
\hline
\end{tabular}

\begin{tabular}{|c|c|c|c|c|c|c|}
\hline \multirow[b]{2}{*}{ Faixas de Renda (SM) } & \multicolumn{3}{|c|}{ IRN Custo $50 \%$} & \multicolumn{3}{|c|}{ IRN Custo $75 \%$} \\
\hline & $\begin{array}{c}G \\
(\mathrm{R} \$)\end{array}$ & $\begin{array}{l}t_{I R N} \\
(\%)\end{array}$ & Benefício (R\$) & $\begin{array}{c}G \\
(\mathrm{R} \$)\end{array}$ & $\begin{array}{l}t_{I R N} \\
(\%)\end{array}$ & Benefício $(\mathrm{R} \$)$ \\
\hline ATÉ 1/4 & & & 55,21 & & & 27,60 \\
\hline DE $1 / 4 A^{1} 1 / 2$ & & & 53,40 & & & 26,70 \\
\hline DE $1 / 2 A 1$ & & & 49,29 & & & 24,64 \\
\hline $\mathrm{DE} 1 \mathrm{~A} 2$ & & & 42,36 & & & 21,08 \\
\hline DE 2 A 3 & 56,61 & 5,7 & 41,80 & 28,31 & 2,8 & 20,10 \\
\hline DE 3 A 5 & & & 30,16 & & & 14,22 \\
\hline DE $5 \mathrm{~A} 10$ & & & 38,43 & & & 57,65 \\
\hline DE 10 A 20 & & & 38,43 & & & 57,65 \\
\hline ACIMA DE 20 & & & 38,43 & & & 57,65 \\
\hline
\end{tabular}

Fonte: Elaboração Própria.

Entretanto, à medida que se adiciona o custo da focalização, o valor do benefício com o Imposto de Renda Negativo vai diminuindo, tornando-se inferior ao da RBC para a maioria das famílias que não poupam, quando o custo ultrapassa $50 \%$. 
Assim, medido pelos recursos transferidos, o IRN é a melhor opção se o custo de focalização for inferior a $25 \%$. Para um custo entre $25 \%$ e $50 \%$, o Imposto de Renda Negativo ainda permanece como opção preferida, mas próximo a $50 \%$ a proposta da Renda Básica da Cidadania já beneficia mais a maioria das famílias. Com custo acima de $50 \%$ a RBC é a melhor escolha.

Deve-se ressaltar que, ao contrário da maioria dos programas sociais que transfere um valor fixo para as famílias identificadas como pobres, o IRN exige também a identificação da renda da família, pois o valor a ser transferido é função da renda familiar. Portanto, é de se supor que um programa social baseado no Imposto de Renda Negativo tenha custo de focalização maior do que os programas mais tradicionais, como o Bolsa-Escola por exemplo, cujo custo estimado fica entre 20 e $25 \% .^{13}$

\subsection{Pobreza e Desigualdade de Renda}

Adotaram-se, aqui, os valores para as linhas de indigência e pobreza de 1/2 e 1 Salário Mínimo por pessoa. Dado o tamanho médio de 3,62 indivíduos por famílias, segundo a POF 2002/2003 do IBGE isto implica uma linha familiar de indigência e pobreza de R\$362,00 e R \$724,00, respectivamente.

A Tabela 3 a seguir apresenta os resultados da adoção das propostas sobre os índices de pobreza $\left(\mathrm{P}^{0}, \mathrm{P}^{1}\right.$ e $\left.\mathrm{P}^{2}\right)$ e desigualdade (Gini).

\section{TABELA 3 - ÍNDICES DE POBREZA E DESIGUALDADE DE RENDA NO LONGO PRAZO}

\begin{tabular}{lccccc}
\hline Indicadores & RBC & IRN s/custo & IRN custo 25\% & IRN custo 50\% & IRN custo 75\% \\
\hline $\mathrm{P}^{0}$ & $-0,77 \%$ & $4,21 \%$ & $3,26 \%$ & $2,25 \%$ & $1,17 \%$ \\
$\mathrm{P}^{1}$ & $-6,95 \%$ & $-0,11 \%$ & $-1,13 \%$ & $-1,98 \%$ & $-1,18 \%$ \\
$\mathrm{P}^{2}$ & $-12,43 \%$ & $-16,82 \%$ & $-14,51 \%$ & $-11,76 \%$ & $-6,30 \%$ \\
GINI & $-2,68 \%$ & $-4,77 \%$ & $-3,80 \%$ & $-2,82 \%$ & $-1,54 \%$ \\
\hline
\end{tabular}

Fonte: elaboração própria.

Analisando a Tabela 3, constata-se que ambas as propostas têm efeitos importantes sobre a pobreza e a desigualdade de renda. Entretanto, quanto ao indicador $\mathrm{P}^{0}$, as propostas têm efeitos contrários. A Renda Básica da Cidadania reduz levemente a

13 Entrevista com Ricardo Paes de Barros, que estima que 20 a $25 \%$ dos que recebem o benefício do bolsa-escola não se enquadrariam no padrão legal de beneficiários. (Valor Econômico, 13/01/2006, página Al0). 
proporção de pobres, enquanto o IRN a aumenta, independente do valor do custo de focalização. Este resultado aparentemente contraditório do IRN decorre do fato de que os desincentivos ao trabalho são maiores maior neste programa no que no do RBC. Como será visto no item seguinte, as famílias beneficiadas pelo IRN reduzem mais intensamente as suas horas de trabalho, o que, dadas as suas preferências, leva a uma redução da renda, incluindo o benefício, com grande aumento nas horas de lazer. $\mathrm{O}$ fato de a introdução ou aumento da generosidade de programas sociais levar ao crescimento da pobreza é um resultado que já foi encontrado nos trabalhos de Bohacek (2002) e Lindbeck (1997). ${ }^{14}$

A redução das horas de trabalho, com o conseqüente aumento na proporção de pobres reflete-se também no indicador do hiato da renda $\left(\mathrm{P}^{\mathrm{l}}\right)$. A redução neste indicador é mais efetiva sob a Renda Básica da Cidadania, mesmo nos casos em que o valor do benefício é menor do que no IRN.

Em termos de intensidade da pobreza, medida pelo hiato quadrático da renda $\left(\mathrm{P}^{2}\right)$, os resultados seguem o valor do benefício para os muito pobres. Nos casos em que o IRN fornece benefícios maiores para estes (renda até 2 S.M.), a redução neste indicador é mais expressiva, enquanto nos casos onde o custo de focalização é de $50 \%$ ou mais, a $\mathrm{RBC}$ leva a reduções maiores. Ressalte-se que apesar da pequena queda ou até aumento no número de pobres, ambas as propostas, em geral, levam a reduções na intensidade da pobreza.

Os resultados nos indicadores de pobreza refletem-se no índice de Gini. A queda na desigualdade mostra-se mais intensa nos casos em que houve maior queda na intensidade da pobreza, refletindo, também, os efeitos do custo de focalização. Quanto menor este custo maior a redução da desigualdade. A redução também foi bastante expressiva para ambas as propostas, com resultados bem razoáveis quando comparada com outras reduçóes observadas na história brasileira, como a promovida pela implantação do Plano Real, que baixou o referido índice em menos de 2\% (0,58 para 0,57 entre 1993 e 1995, conforme mostrou ROCHA, 2000). Tais resultados estão razoavelmente próximos aos obtidos por Muller et al. (2004), que realizou simulações para a economia suíça usando a modelagem de equilíbrio geral computável, tendo encontrado efeitos mais importantes sobre a desigualdade no caso de um IRN do que com um programa de renda universal.

14 Bohacek (2002) obtém resultados interessantes sobre o nível do consumo mínimo garantido e a quantidade de pobres. Segundo este autor, o número de pobres reduz-se com o aumento do consumo mínimo somente até certo ponto ( $22 \%$ do consumo médio familiar), e acima deste valor o número de pobres aumenta. Da mesma forma, Lindbeck (1997), ao analisar a evolução do sistema de seguridade social sueco, verificou que o aumento da generosidade dos programas levou ao incremento do número de famílias pobres. O autor atribuiu este resultado aos efeitos negativos das políticas de bem-estar sobre a educação, oferta de trabalho e participação no mercado de trabalho. 


\subsection{Aspectos Macroeconômicos}

A maioria dos estudos existentes acerca dos efeitos das políticas sociais normalmente analisa apenas os impactos das propostas sobre os indicadores de pobreza e desigualdade de renda, sem se preocupar com os efeitos indiretos sobre a economia como um todo. A partir do momento em que se adota uma abordagem de equilíbrio geral, esses efeitos vêm à tona e a análise torna-se mais rica. Vejamos, pois, como cada uma das políticas propostas neste estudo afeta o consumo, as horas de trabalho e o produto. Na Tabela 4 a seguir são apresentados os resultados de cada proposta.

TABELA 4 - EFEITOS MACROECONÔMICOS (EM \%)

\begin{tabular}{|c|c|c|c|c|c|c|c|c|c|c|c|c|c|c|c|}
\hline \multirow{2}{*}{ Ano } & \multicolumn{3}{|c|}{ RBC } & \multicolumn{3}{|c|}{$\mathrm{N} \mathrm{s} / \mathrm{cus}$} & \multicolumn{3}{|c|}{ IRN custo $25 \%$} & \multicolumn{3}{|c|}{ IRN custo $50 \%$} & \multicolumn{3}{|c|}{ IRN custo } \\
\hline & C & $\mathrm{H}$ & $Y$ & C & $\mathrm{H}$ & $Y$ & C & $\mathrm{H}$ & Y & C & $\mathrm{H}$ & Y & C & $\mathrm{H}$ & Y \\
\hline 3 & & & & & & & & & & & & & & & 075 \\
\hline 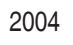 & & & & & & & & & & & & & & & \\
\hline 0 &,, 0 & 1,00 & & 1,00 & 1,00 & & & $-1,0 L$ & & 0,04 & $-1,01$ & 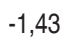 & 0,82 & $-1,00$ & (נ, \\
\hline 00 & $1, \angle 0$ & r ו & &,, 00 & 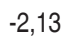 & 2,1 & 0,86 & $2, \infty$ & $L_{2}$ & Or & $-<, \cup 0$ & 2,00 & & & -2 \\
\hline 10 & 1,21 & $-1,09$ & $-1,67$ & 0 & $-3,91$ & $-3, c$ & 0,79 & $-3, J I$ & $-2,01$ & 84 & $-2,85$ & $-2,55$ & 30 & -2 & $-<, 4$ \\
\hline 012 & 1,23 & $-1,74$ & $-1, \varepsilon$ & 0,60 & $-3,92$ & $-3,35$ & 0,68 & $-3,34$ & $-2,93$ & 0,77 & $-2,83$ & $-2,59$ & 77 & $-2,54$ & $-2,43$ \\
\hline 020 & 1,30 & $-1,76$ & $-1,8$ & 21 & $-3,80$ & $-3,56$ & 0,41 & $-3,25$ & $-3,08$ & 0,61 & $-2,78$ & $-2,68$ & 0,70 & $-2,52$ & $-2,47$ \\
\hline 040 & 1,35 & $-1,78$ & -1 , & $-0,03$ & $-3,73$ & $-3,70$ & 0,24 & $-3,20$ & $-3,18$ & 0,50 & $-2,74$ & $-2,73$ & 0,65 & $-2,50$ & $-2,50$ \\
\hline 060 & 35 & 1,78 & 78 & 0,06 & $-3,72$ & $-3,71$ & ,22 & $-3,19$ & $-3,19$ & 0,49 & $-2,74$ & $-2,74$ & 0,65 & $-2,50$ & $-2,50$ \\
\hline
\end{tabular}

Fonte: elaboração própria.

Como já visto, os dois programas sociais têm o mesmo custo e foram financiados pela redução dos gastos públicos. A principal causa dos diferentes resultados macroeconômicos das duas propostas está assentada na resposta ótima das horas de trabalho das famílias à introdução dos dois programas. Isto pode ser visto reunindo as equações (21) e (22):

$$
h_{i t}=1-\frac{\left(1-\alpha_{i}\right) T_{i t}}{\left(1-\tau_{h t}^{i}\right) w_{i t}}
$$

Com a introdução da RBC e do IRN, tem-se as seguintes equações:

$$
h_{R B C}=1-\frac{\left(1-\alpha_{i}\right)\left(T_{i t}+\Delta T\right)}{\left(1-\tau_{h t}^{i}\right) w_{i t}} \quad h_{I R N}=1-\frac{\left(1-\alpha_{i}\right)\left(T_{i t}+G\right)}{\left(1-\tau_{h t}^{i}-t\right) w_{i t}}
$$


Percebe-se que o IRN afeta mais negativamente as horas de trabalho das famílias do que a RBC. Independente do custo de focalização, a trajetória das horas de trabalho na Renda Básica da Cidadania é sempre mais favorável do que no Imposto de Renda Negativo. Isto porque o IRN reduz o salário líquido (denominador) e aumenta mais as transferências (numerador), pois na maioria dos casos analisados $\mathrm{G}>\Delta \mathrm{T}$. Este efeito negativo da introdução de programas de bem-estar social ocorre basicamente por dois motivos: (i) o valor do benefício relativamente alto em relação à renda salarial que o indivíduo obteria no mercado de trabalho e (ii) alíquota de redução do benefício, $\mathrm{t}_{\mathrm{IRN}}$, elevada. A combinação destes dois efeitos cria o que foi chamado de "armadilha de pobreza" (BOETERS et al., 2004) e representa uma barreira para o emprego daqueles que se beneficiam com esses programas. Assim, quanto maior $G$ e $t$, menor a quantidade de horas trabalhadas.

Em termos macroeconômicos, no lado da oferta de fatores, a escassez relativa do trabalho eleva seu preço em comparação com o capital e esse desajuste força paulatinamente a redução do estoque de capital. Com menos emprego e capital, o produto cai durante todo o período. Do lado da demanda, no curto prazo, antes do aumento das transferências já ocorre redução das horas de trabalho e aumento do consumo das famílias que poupam, antecipando os benefícios futuros. Dado que a despesa do governo ainda está constante e ocorre queda na produção com aumento do consumo, há expressiva redução do investimento. Na primeira rodada das transferências, em 2005, as horas trabalhadas aceleram a queda e o consumo aumenta ainda mais, reduzindo o produto e as despesas governamentais, mas recuperando o investimento que, entretanto, continua em nível inferior ao de 2002. Após 2010, as horas de trabalho se estabilizam, com queda gradativa do capital e do produto. As despesas do governo atingem o seu novo patamar, mais baixo que o anterior, de forma a compensar os benefícios concedidos pelos novos programas (IRN ou RBC), com o investimento se estabilizando em nível inferior ao inicial e consumo aumentando no longo prazo.

Como a RBC reduz menos intensamente as horas trabalhadas, acaba diminuindo menos o estoque de capital e o produto, mantendo uma renda maior para as famílias. Com mais renda, o consumo cresce. Já o IRN produz maior queda nas horas de trabalho, afetando negativamente o estoque de capital, o produto e a renda das famílias, levando a um reduzido crescimento do consumo. Observa-se que quanto maior o custo de focalização menor $\mathrm{G}$ e $\mathrm{t}$, o que leva a uma redução menor das horas de trabalho e a melhores resultados no produto e no consumo, aproximando-se dos resultados obtidos pela $\mathrm{RBC}$, mas ainda inferiores. Quedas mais intensas nas horas 
de trabalho e no produto para o caso do IRN também foram observadas no trabalho de Muller et al. (2004) para a economia suíça. ${ }^{15}$

\section{CONCLUSÕES}

O artigo procurou comparar duas políticas sociais alternativas de combate à pobreza e à desigualdade. A primeira, a concessão de uma renda fixa paga universalmente a todos os brasileiros, denominada Renda Básica da Cidadania, e a segunda, um imposto de renda negativo, pago apenas às famílias com renda inferior a um determinado patamar. Para esta última, considerou-se o custo de focalização e os seus efeitos sobre os resultados.

A primeira proposta mostrou resultados melhores que a segunda, quando o custo de focalização desta era superior a $50 \%$, resultando em maior valor do benefício, indicadores de pobreza e desigualdade mais favoráveis e resultados menos ruins do ponto de vista macroeconômico. Estes números indicam que a RBC seria o programa social mais adequado se o custo de focalização do IRN fosse maior que $50 \%$.

Quando este se situa entre 0 e $50 \%$, já não há uma indicação clara de qual programa deveria ser adotado. Isto porque a RBC fornece benefícios menores e leva a uma menor redução da intensidade da pobreza e desigualdade, mas, em contrapartida, tem efeitos mais positivos sobre a proporção de pobres e o hiato da pobreza, além de resultados muito superiores em termos macroeconômicos. Já o IRN, apesar de desestimular fortemente o trabalho e reduzir o produto, é mais efetivo no auxílio aos muito pobres e na diminuição da desigualdade, embora provoque um aumento na proporção de pobres. Neste caso, caberá ao formulador da política ponderar qual o preço aceitável, em termos de eficiência, e que ganhos importam no combate à pobreza e desigualdade para definir qual alternativa seguir.

Em decorrência do forte desestímulo ao trabalho trazido por programas sociais que utilizem apenas a renda como principal parâmetro para o cálculo do benefício (como a proposta do IRN neste artigo), pesquisas recentes, como a de Kleven e Kreiner (2005), realçam que a política de concessão de benefícios associados apenas aos pobres que trabalham, como no programa EITC norte-americano, tem ocupado espaço cada vez maior na agenda de programas de bem-estar europeus pelos bons resultados tanto em termos de eficiência quanto de eqüidade. Há, entretanto, questionamentos em relação à situação daqueles que estão presos ao desemprego involuntário e aos que

15 Sob o IRN as horas de trabalho e o produto encolheram $6 \%$ e 5,6\%, respectivamente, enquanto com a renda universal a queda foi de $-2,2 \%$ e $-2,6 \%$. 
não podem trabalhar, já que propostas deste tipo podem trazer perda de bem-estar para grupos sociais que já vivem com grande dificuldade. Futuras pesquisas podem avançar na análise e comparação de programas focados nos pobres que trabalham em relação a outros programas mais universais.

\section{ANEXO - CALIBRAGEM DOS PARÂMETROS}

A distribuição das famílias, dada no modelo pelo parâmetro $\eta$, está apresentada na Tabela $1 \mathrm{~A}$ a seguir. ${ }^{16}$ As famílias 1 a 6 não poupam e as famílias 7 a 9 poupam. ${ }^{17}$

$$
\begin{aligned}
\text { TABELA } & \text { IA - DIVISÃO DAS FAMÍLIAS E REPRESENTAÇÃO DA } \\
& \text { POPULAÇÃO }
\end{aligned}
$$

\begin{tabular}{lccccccc}
\hline Família & $\begin{array}{c}\text { Faixa de } \\
\text { Renda (SM) }\end{array}$ & $\begin{array}{c}\text { Número de } \\
\text { Famílias }\end{array}$ & $\begin{array}{c}\text { Proporção de } \\
\text { Famílias (\%) }\end{array}$ & Família & $\begin{array}{c}\text { Faixa de Renda } \\
\text { (SM) }\end{array}$ & $\begin{array}{c}\text { Número de } \\
\text { Famílias }\end{array}$ & $\begin{array}{c}\text { Proporção de } \\
\text { Famílias (\%) }\end{array}$ \\
\hline 01 & Até $1 / 4$ & 1.230 .937 & $2,54 \%$ & 06 & 35 & 10.181 .484 & $20,98 \%$ \\
02 & $1 / 4$ a $1 / 2$ & 337.597 & $0,70 \%$ & 07 & 5 a 10 & 11.964 .924 & $24,65 \%$ \\
03 & $1 / 2$ a 1 & 2.530 .902 & $5,21 \%$ & 08 & 10 a 20 & 6.987 .605 & $14,40 \%$ \\
04 & 1 a a 2 & 3.849 .916 & $7,93 \%$ & 09 & Mais de 20 & 4.704 .154 & $9,69 \%$ \\
05 & 2 a 3 & 6.747 .421 & $13,90 \%$ & Total & & 48.534 .639 & $100,00 \%$ \\
\hline
\end{tabular}

Fonte: Pesquisa de Orçamentos Familiares (POF) e Censo 2000.

\section{A.I DEPRECIAÇÃO}

Para se obter a depreciação lançou-se mão do uso de um algoritmo adotado por Paes (2004), calculando-se a depreciação em $\delta=5,54 \%$.

16 Para a determinação das quatro primeiras faixas de renda utilizou-se a distribuição do Censo 2000 de maneira a subdividir a primeira faixa de renda da Pesquisa Orçamentária Familiar (POF) do IBGE.

17 Segundo dados da POF 2002/2003, as famílias com rendimento superior a 6 SM possuem renda maior que as despesas de consumo. Dessa forma, adotou-se como ponto de corte para as famílias que não poupam a faixa de 3 a $5 \mathrm{SM}$, uma vez que a faixa seguinte, de 5 a $10 \mathrm{SM}$, já seria composta em sua maioria por famílias com capacidade de poupança. Observe que a escolha de 5 SM como ponto de corte entre as famílias que poupam e as que não poupam também divide as famílias entre as que não pagam e as que pagam Imposto de Renda Pessoa Física (IRPF), já que, em 2002, o salário mínimo era de R\$ 200,00 e a faixa de isenção do IRPF era de R\$ $1.058,00$. 


\section{A.2 HORAS TRABALHADAS}

As horas trabalhadas para cada família foram determinadas utilizando-se os dados do Censo 2000 do IBGE, com as informações do número de horas trabalhadas por ocupação, obtendo-se, então, a quantidade média de horas trabalhadas por cada ocupação, juntamente com os dados da distribuição das ocupações por faixa de renda. Para este modelo, preferiu-se trabalhar com a relação total de horas trabalhadas por total de horas mensais.

TABELA 2A - HORAS TRABALHADAS POR FAIXA DE RENDA

\begin{tabular}{lccccccccc}
\hline Faixa de Renda (SM) & Até 1/4 & $1 / 4$ a $1 / 2$ & $1 / 2$ a 1 & 1 a 2 & 2 a 3 & 3 a 5 & 5 a 10 & 10 a 20 & $>20$ \\
\hline Horas Trabalhadas & 0,2476 & 0,2476 & 0,2476 & 0,2502 & 0,2509 & 0,2501 & 0,2488 & 0,2489 & 0,2494 \\
\hline
\end{tabular}

Fonte: Censo 2000.

\section{A.3 CONSUMO DESAGREGADO}

Segundo dados das Contas Nacionais do IBGE, a relação consumo das famílias/ PIB foi de 60,15\% em 2002. Para se determinar qual seria esta relação para cada família utilizaram-se os dados da POF/IBGE. O resultado pode ser visto na tabela a seguir:

\section{TABELA 3A - CONSUMO DAS FAMÍLIAS}

\begin{tabular}{lrrrrrrrrr}
\hline Faixas de Renda (SM) & Até 1/4 & $1 / 4$ a $1 / 2$ & $1 / 2$ a 1 & 1 a 2 & 2 a 3 & 3 a 5 & 5 a 10 & 10 a 20 & $>20$ \\
\hline Consumo Total - POF (R\$) & 37,83 & 86,32 & 196,98 & 388,12 & 491,25 & 770,79 & $1.395,90$ & $2.708,12$ & $6.688,38$ \\
Consumo Líquido (R\$) & 31,18 & 71,15 & 162,37 & 319,92 & 406,30 & 637,41 & $1.150,01$ & $2.226,44$ & $5.559,81$ \\
Ci/Y & 0,0137 & 0,0313 & 0,0714 & 0,1406 & 0,1786 & 0,2802 & 0,5055 & 0,9787 & 2,4441 \\
\hline
\end{tabular}

Fonte: POF 2002-2003.

Os dados de consumo total e do percentual do consumo tributado (despesas de consumo) foram obtidos da POF. Consideraram-se todos os itens de consumo como tributados, exceto impostos, contribuições trabalhistas, previdência privada e pagamentos de pensões, mesadas, aluguel e doações. ${ }^{18} \mathrm{O}$ consumo líquido é calculado descontando-se a tributação sobre a parcela do consumo total que é tributada e adicionando-se a parcela do consumo total que não é tributada. A relação $C / \Upsilon$ para

18 Considerou-se como alíquota da tributação do consumo a disposta na Tabela 7A. É necessário ressaltar que se trata de uma média, uma vez que as alíquotas do consumo são diferenciadas de acordo com o produto e com o Estado (ICMS) ou o município (ISS). 
a economia brasileira em 2002 foi de 60,15\%, e representa a média ponderada do consumo líquido em relação ao produto tendo como pesos a distribuição da população, o que nos permite calcular a relação consumo das famílias/PIB, dada por $C i / \Upsilon$, para cada uma delas.

\section{A.4 SALÁRIO DESAGREGADO}

Para o cálculo do salário desagregado foram utilizados os dados da POF/IBGE relativos aos rendimentos. Inicialmente classificou-se cada tipo de rendimento, de forma a identificar aqueles que são oriundos do trabalho (incluindo aqui o rendimento não monetário) e, a partir deste, obteve-se a seguinte distribuição salarial:

TABELA 4A-DISTRIBUIÇÃO DOS SALÁRIOS

\begin{tabular}{lrrrrrrrrr}
\hline Faixa de Renda (SM) & Até 1/4 & $1 / 4$ a $1 / 2$ & $1 / 2$ a 1 & 1 a 2 & 2 a 3 & 3 a 5 & 5 a 10 & 10 a 20 & $>20$ \\
\hline Rendimento Trabalho (R\$) & 31,61 & 72,13 & 164,60 & 324,32 & 401,70 & 668,27 & $1.177,07$ & $2.214,27$ & $5.631,16$ \\
$W / Y$ & 0,0561 & 0,1281 & 0,2923 & 0,5698 & 0,7039 & 1,1744 & 2,0796 & 3,9101 & 9,9239 \\
\hline
\end{tabular}

Fonte: POF 2002-2003.

Dividindo o rendimento do trabalho pelo consumo líquido calculado no item anterior obteve-se a relação $W H / C$. Multiplicando este valor pela relação $C / Y$ obteve-se $W H / Y$, que dividido por $H$ fornece o salário por semana por família $W / Y$. Pode-se também determinar o valor do salário médio, que é a média ponderada dos salários das famílias, $w=2,4444$.

\section{A.5 PARTICIPAÇÃO DA RENDA DO CAPITAL NO PRODUTO. ESTOQUE DE CAPITAL. PRODUTO. TAXA DE JUROS}

Para a determinação da participação do capital no produto $(\theta)$ utilizou-se do fato de que $\theta=1-w h / y$. Assim, como $w / y=2,4444$ e $\mathrm{h}=0,2493$, obtém-se $\theta=0,3905$.

Já o estoque de capital $K$ foi calculado com o auxílio das equações da acumulação de capital (9), da função de produção e do fato de que em 2002 a relação Investimento / PIB foi de $18,99 \%$. Dado $\theta$, obtém-se $K=1,8805$.

O produto decorre diretamente da função de produção (14), de forma que $Y=$ 0,5489 . Portanto, a relação capital-produto, $K / Y$, vale 3,4262 . 
A taxa de juros pode ser calculada através da equação (15), de onde se tem $r=$ $11,40 \%$.

\section{A.6 TRIBUTAÇÃO}

Cada família terá alíquotas diferenciadas de imposto de renda e consumo, e as famílias que poupam estarão sujeitas, também, a uma alíquota única do imposto sobre a renda do capital. A distribuição da carga fiscal em 2002 por fato gerador (renda do trabalho, renda do capital e consumo) proposta por Paes (2004) está resumida na Tabela $5 \mathrm{~A}$ a seguir:

TABELA 5A - RESUMO DA DISTRIBUIÇÃO DA CARGA TRIBUTÁRIA

\begin{tabular}{lc}
\hline Fato Gerador & Percentual do PIB \\
\hline Imposto sobre a Renda do Trabalho & $10,71 \%$ \\
Imposto sobre a Renda do Capital & $7,84 \%$ \\
Imposto sobre o Consumo & $17,31 \%$ \\
\hline
\end{tabular}

Fonte: Elaboração Própria.

A tributação sobre a renda do trabalho foi dividida em duas partes: uma fixa e uma variável. A primeira corresponde aos tributos pagos sobre a folha de pagamento no total de $8,51 \%$ do PIB. ${ }^{19}$ Assim, dado o produto e a renda do trabalho, tem-se $\tau_{h}^{F}=13,96 \%$. A parte variável corresponde ao Imposto de Renda Pessoa Física (IRPF), e, com os dados agregados da Declaração de Imposto de Renda Pessoa Física 2002, calcula-se a alíquota efetiva sobre a renda do trabalho:

TABELA 6A - ALÍQUOTAS DO IMPOSTO SOBRE A RENDA DO TRABALHO

\begin{tabular}{lrrrrrrrrr}
\hline Faixa de Renda (SM) & Até 1/4 & $1 / 4$ a $1 / 2$ & $1 / 2$ a 1 & 1 a 2 & 2 a 3 & 3 a 5 & 5 a 10 & 10 a 20 & $>20$ \\
\hline Alíquota Fixa (\%) & 13,96 & 13,96 & 13,96 & 13,96 & 13,96 & 13,96 & 13,96 & 13,96 & 13,96 \\
Alíquota Variável (\%) & 0,00 & 0,00 & 0,00 & 0,00 & 0,00 & 0,00 & 0,92 & 3,26 & 6,76 \\
Alíquota Total (\%) & 13,96 & 13,96 & 13,96 & 13,96 & 13,96 & 13,96 & 14,88 & 17,22 & 20,72 \\
\hline
\end{tabular}

Fonte: Elaboração Própria.

19 Nós os consideramos fixos porque há muito pouca ou nenhuma diferenciação das alíquotas entre as famílias. Todas pagam $8 \%$ de FGTS, 2,5\% de Salário Educação, 3,1\% do Sistema S, 20\% da contribuição patronal ao INSS e de 8 a 11\% de contribuição do empregado para a Previdência Social. 
Conforme determinado previamente, o imposto sobre a renda do capital representou $7,84 \%$ do PIB em 2002. Dados o produto e a renda do capital, obtém-se $\tau_{k}=$ $20,08 \%$.

Assim como no caso da tributação da renda do trabalho, dividiu-se a tributação do consumo em duas partes, uma fixa ${ }^{20}$ e outra variável, ${ }^{21}$ seguindo-se a metodologia utilizada por Paes e Bugarin (2006).

Utilizando dados da SRF e a desagregação das despesas de consumo conforme a POF, obtiveram-se as alíquotas efetivas de cada um desses tributos para cada uma das famílias, que, somados à parte fixa, fornecem a alíquota efetiva sobre o consumo das famílias de acordo com a tabela a seguir.

\section{TABELA TA - TRIBUTAÇÃO DO CONSUMO - PARTE VARIÁVEL POR FAMÍLIA ${ }^{22}$}

\begin{tabular}{lrrrrrrrrr}
\hline Faixa de Rendimentos & Até $1 / 4$ & $1 / 4$ a $1 / 2$ & $1 / 2$ a 1 & 1 a 2 & 2 a 3 & 3 a 5 & 5 a 10 & 10 a 20 & $>20$ \\
\hline ISS (\%) & 0,79 & 0,79 & 0,79 & 0,79 & 0,83 & 0,93 & 1,14 & 1,31 & 1,59 \\
ICMS (\%) & 13,23 & 13,23 & 13,23 & 13,23 & 13,32 & 13,42 & 13,50 & 13,35 & 12,45 \\
IPI (\%) & 2,14 & 2,14 & 2,14 & 2,14 & 2,15 & 2,20 & 2,34 & 2,45 & 2,39 \\
PIS/COFINS (\%) & 7,16 & 7,16 & 7,16 & 7,16 & 7,09 & 7,09 & 7,22 & 7,44 & 7,60 \\
CPMF (\%) & 1,30 & 1,30 & 1,30 & 1,30 & 1,31 & 1,31 & 1,31 & 1,32 & 1,32 \\
Alíquota - Parte Fixa (\%) & 3,39 & 3,39 & 3,39 & 3,39 & 3,39 & 3,39 & 3,39 & 3,39 & 3,39 \\
Alíquota Efetiva Total (\%) & 28,01 & 28,01 & 28,01 & 28,01 & 28,08 & 28,35 & 28,90 & 29,27 & 28,74 \\
\hline
\end{tabular}

Fonte: POF 2002-2003 e SRF.

\section{A.7 DEMAIS PARÂMETROS E VARIÁVEIS}

Para o cálculo do estoque de capital das famílias no estado estacionário recorreu-se às equações de restrição orçamentária intertemporal das famílias que poupam (8).

$20 \mathrm{O}$ que se denomina parte fixa da tributação sobre o consumo são aqueles tributos que não são individualizados por cada tipo de bem. Nesta categoria estão os impostos sobre o comércio exterior, taxas federais, estaduais e municipais, além dos tributos classificados em outros na tabela 1 de Paes (2004), representando, em conjunto, $2,04 \%$ do PIB. A alíquota efetiva é obtida dividindo-se este percentual pela participação do consumo no PIB.

21 Na parte variável estão o PIS, a COFINS, a CPMF, o ICMS, o ISS e o IPI, que representam conjuntamente $15,27 \%$ do PIB. Em cada caso, deve-se determinar a alíquota do imposto que será aplicada a cada item de despesa da POF.

22 Como a primeira faixa da POF engloba famílias até 2 S.M., adotou-se a mesma cesta de consumo para todas as famílias com renda abaixo deste limite, o que implica alíquotas efetivas idênticas para este grupo de famílias. 
As transferências públicas para as famílias dos tipos I e II podem ser calculadas através das restrições orçamentárias, equações (2) e (5). Para as famílias do tipo III, calculou-se o valor das transferências totais da economia usando a restrição orçamentária do governo. Deste total, descontaram-se os valores transferidos às famílias que não poupam e em seguida distribuiu-se o restante entre as famílias que poupam de acordo com o valor do item Aposentadoria da Previdência Pública da POF.

As despesas do governo podem ser obtidas da restrição agregada (18), que fornece $g=0,1145$, o que equivale a $20,86 \%$ do PIB.

A taxa de desconto intertemporal sai da equação do consumo das famílias tipo III (20), de onde se obtém $\beta=0,9656$.

O consumo mínimo equivale ao valor em $\mathrm{R} \$$ da linha de indigência e separa as famílias dos tipos I e II. Como já visto, adotou-se aqui a linha de indigência per capita de $1 / 2$ salário mínimo, o equivalente a $\mathrm{R} \$ 100,00 \mathrm{em} 2002$. Dado que, segundo os dados da POF, cada família tem em média 3,62 membros, a linha de indigência familiar seria de $\mathrm{R} \$ 362,00$, que no modelo equivale a um consumo mínimo de 0,1112. Este valor inclui os tributos sobre o consumo. Com o dados da Tabela 3 corrigidos para se retirar o valor do produto e considerando-se a tributação, concluise que as famílias do tipo I englobam aquelas com renda de até 2 S.M., enquanto as com renda entre 2 e 5 S.M. pertencem ao tipo II .

O peso do consumo na função utilidade das famílias tipos II e III, $\alpha_{i}$, pode ser calculado mediante as equações de horas de trabalho (20) e (22), enquanto o peso do governo, $\gamma_{i}$, pode ser calculado supondo que a relação entre a utilidade marginal do consumo dos agentes e a utilidade marginal dos gastos do governo seja igual à relação entre os preços do consumo e o preço pago pelas famílias pelo gastos do governo. ${ }^{23}$ Finalmente, a produtividade do trabalho das famílias pode ser calculada utilizando a equação dos salários (14). Tudo está demonstrado na Tabela 8A.

23 Segundo Pedersen (1999), esta igualdade é "uma condição padrão em finanças públicas na qual a utilidade marginal do consumo de bens públicos e privados é igual no estado estacionário". 


\section{TABELA $8 A$ - DISTRIBUIÇÃO DO CAPITAL ENTRE AS FAMÍLIAS}

\begin{tabular}{lrrrrrrrrr}
\hline Faixa de Rendimentos & Até $1 / 4$ & $1 / 4$ a $1 / 2$ & $1 / 2$ a 1 & 1 a 2 & 2 a 3 & 3 a 5 & 5 a 10 & 10 a 20 & $>20$ \\
\hline Estoque de Capital & 0 & 0 & 0 & 0 & 0 & 0 & 1,6444 & 4,2299 & 8,9675 \\
Transferências & 0,0031 & 0,0070 & 0,0160 & 0,0315 & 0,0422 & 0,0587 & 0,0573 & 0,1013 & 0,3299 \\
Peso do Consumo & 1,0000 & 1,0000 & 1,0000 & 1,0000 & 0,3352 & 0,3219 & 0,3289 & 0,3423 & 0,3476 \\
Peso do Governo & 15,2193 & 6,6702 & 2,9230 & 1,4835 & 0,3916 & 0,2397 & 0,1357 & 0,0730 & 0,0297 \\
Produtividade & 0,0230 & 0,0524 & 0,1196 & 0,2331 & 0,2880 & 0,4804 & 0,8508 & 1,5996 & 4,0598 \\
\hline
\end{tabular}

Fonte: POF 2002-2003 e SRF.

\section{REFERENCIAS}

ADELMAN, I.; ROBINSON, S. Income distribution and growth: a case study of Korea. Oxford: Oxford University Press, 1976.

BARROS, R. P.; COURSEIL, C. H.; CURY, S. Salário mínimo e pobreza no Brasil: uma abordagem de equilíbrio geral. Pesquisa e Planejamento Econômico, v. 30, n. 2, p. 157-182, 2000.

BOETERS S.; FEIL, M.; GÜRTZGEN, N. Discrete working time choice in an Applied General Equlibrium Model. In: ZEW Discussion Paper n. 04-20, 2004.

BOHACEK, R. The efficiency-equality tradeoff in welfare state economies. In: Econ WPA Macroeconomic Series n. 0203001, mar. 2002.

BOURGUIGNON, F.; MELO, J.; SUWA, A. Modelling the effects of adjustment programmes on income distribution. World Development, v. 19, n. 11, p. 1527 $1544,1991$.

CURY, S. Modelo de equilibrio geral para simulação de politicas de distribuição de renda e crescimento no Brasil. 1998. Tese (Doutorado em Economia) - Escola de Administração de Empresas de São Paulo, Fundação Getúlio Vargas. São Paulo.

EISSA, N.; KLEVEN, H. J.; KREINER, C. T. Welfare effects of tax reform, and labor supply at the intensive and extensive margins. In: AGELL, J.; SØRENSEN, P.B. (eds). Tax policy and labour market performance, Cambridge: MIT Press, forthcoming, 2005.

FOSTER, J.; GREER, J.; THORBECKE, E. A class of decomposable poverty measures. Econometrica, v. 52, n. 3, p.761-766, 1984.

FRIEDMAN, M. Capitalismo e liberdade. Rio de Janeiro: Editora Arte Nova, 1975.

HARBERGER, A. C. Reflections on distributional considerations and the public finances. Paper Prepared For a Course On Practical Issues Of Tax Policy In Developing Countries. The World Bank, 2003. 
HENRIQUES, R. (org.). Desigualdade e pobreza no Brasil. Rio de Janeiro: IPEA, 2000.

HOFFMANN, R. Distribuição de renda: medidas de desigualdade e pobreza. São Paulo: Edusp, 1998. 275 p. (Academia, 22).

IBGE. Pesquisa de Orçamentos Familiares 2002/2003. Rio de Janeiro, 2004.

KHAN, H.A. Sectoral growth and poverty: a multiplier decomposition analysis for South Africa. World Development, v. 27, n. 3, p.138-154, 1999.

KLEVEN, H. J., KREINER, C. T. Labor supply behavior and the design of tax and transfer policy. University of Copenhagen Working Paper, 2005.

LAVINAS, L. Combinando compensatório e redistributivo: o desafio das políticas sociais no Brasil. In: Seminário Desigualdade e Pobreza no Brasil, 1999, Rio de Janeiro. Anais. Rio de Janeiro: Coord. Ricardo Henriques, IPEA, 1999.

LINDBECK, A. The swedish experiment. Journal of Economic Literature, v.35, n.3, p.1273-1319, 1997.

MOFFITT, R. A. The negative income tax and the evolution of U.S. welfare policy. Journal of Economic Perspectives, v. 17, n. 3, p. 119-140, 2003.

MULLER, T.; NAGA, R. A.; BAALEN, B.; KOLDZIEJCZYK, C. Economic effects of different proposals for the reform of the social security system in Switzerland. National Research Program 45, 2004.

NERI, M. Mapa do fim da fome 2. FGV/ EPGE, 2001.

PAES, N. L. Reforma tributária: aspectos distributivos e de bem-estar. 2004. Tese (Doutorado em Economia) - Universidade de Brasília - UnB. Brasília.

; BUGARIN, M. S. Parâmetros tributários brasileiros. Estudos Econômicos, São Paulo, v. 36 n. 4 p. 699-720, out/dez 2006.

PEDERSEN, M. T. Understanding business cycle. Classes Notes, 1999. Disponível em: <http://www.econ.ku.dk/tmp/Understand/understandingbusinesscycles. htm $>$.

ROCHA, S. Pobreza e desigualdade no Brasil: o esgotamento dos efeitos distributivos do plano real. Rio de Janeiro: IPEA, 2000. (Texto para Discussão, n. 721).

SUPLICY, E. M. Renda básica da cidadania. Porto Alegre: L\&PM, 2006. . Renda de cidadania - a saida é pela porta. São Paulo: Editora Perseu Abramo, 2002. 